\title{
In Perspective: Connected Growth: developing a framework to drive inclusive growth across a city-region
}

By David Beel ${ }^{1}$ (Staffordshire University), Martin Jones (Staffordshire University), lan Rees Jones (Cardiff University) and Warren Escadale (VSNW)

\begin{abstract}
This 'in perspective' piece addresses the (re-)positioning of civil society within new structures of city-region governance within Greater Manchester (GM). This follows on from the processes of devolution, which have given the Greater Manchester City-Region (GMCR) a number of new powers. UK devolution, to date, has been largely focused upon engendering agglomerated economic growth at the city-region scale. Within GMCR, devolution for economic development has sat alongside the devolution of health and social care (unlike any other city-region in the UK) as well. Based on stakeholder mapping and semi-structured interviews with key actors operating across the GMCR, the paper illustrates how this has created a number of significant tensions and opportunities for civil society actors, as they have sought to contest a shifting governance framework. The paper, therefore, calls for future research to carefully consider how civil society groups are grappling with devolution; both contesting and responding to devolution. This is timely given the shifting policy and political discourse towards the need to deliver more socially-inclusive city-regions.
\end{abstract}

\section{Key words:}

City-region; civil society; inclusive growth; city-region building

\footnotetext{
${ }^{1}$ Corresponding author - e:david.beel@staffs.ac.uk, a:Geography, Staffordshire University, Leek Road, Stoke-on-Trent, ST4 2DF.
} 


\section{Connected Growth: developing a framework to drive inclusive growth across a city-region}

\section{Introduction}

In recent months, the city-region building agenda appears to be showing more of an interest in the voluntary and third sector as partners. A Green Paper on the interfaces between employment and health calls for an understanding of how to best support people with health conditions or those deemed disabled to return to or stay in work. This includes finding ways 'to extend the reach of Jobcentre Plus into third sector support groups which are already well established' (DWP, 2016:29-30). The Greater Manchester (GM) model is particularly interesting here and its specifics will be influencing new trials in the Sheffield City-region and the West Midlands Combined Authority during 2017 for a period of between 2 and 3 years (see Sheffield.ac.uk, 2016). These are developments in the inclusive growth policy-fields (see RSA, 2016a, 2016b, 2016c), which we are keen to watch and this paper focuses on the positioning of civil society, third sector, and voluntary sector actors in the Greater Manchester City Region (GMCR)/Greater Manchester Combined Authority (GMCA), with a view to informing debates across England and beyond ${ }^{2}$.

Devolution to the GMCR to date has been a centrally led process with only minimal and piecemeal consultation (Waite, Maclennan, \& O'Sullivan, 2013). The process of devolution will create a variety of new policy opportunities for the region but the initial variety of devolution has been geared more toward economic growth (Bailey \& Budd, 2016). In doing this and especially given the opportunities provided by the devolution of health and welfare, there is a recognised need to bring together the appropriate voices within the city-region to address the problems of inequality faced by the region. Devolution, to date, has been framed and shaped by central government in terms of what they see as the appropriate pathway to growth, through a deal making process of negotiation (O'Brien \& Pike, 2015). Unfortunately, this pathway is largely dependent upon an economic model focussed on enhancing processes of agglomeration which in turn only serves to further create uneven development within the city-region (Etherington \& Jones, 2016b; Haughton, Deas, Hincks, \& Ward, 2016). If growth is to be inclusive, this model has to change and devolution has to find ways to offer opportunities that significantly move beyond the model that has been laid out by central government (Beel, Jones, \& Jones, 2016; Jonas, 2012).

In interviews with members of the Greater Manchester Voluntary, Community and Social Enterprise (VCSE) Devolution Reference Group the following paper, will argue, that there is currently a need - which is endorsed by local partners and underway - to bring different third and voluntary sector organisations into processes of devolution (cf. Dear \& Wolch, 1987; DeVerteuil, 2016; Jones, 2012). The work of Dear \& Wolch (1987) especially,

\footnotetext{
${ }^{2}$ Civil Society is used as a catch all term for a number of different organisations this includes voluntary sector, community groups, social enterprise, non-profits, and trade unions (Heinrich, 2005; Jones, 2012).
} 
represents an important framing point to this paper and more broadly, the current conjuncture. This is because they followed the trajectory of neo-liberalisation of inner-city welfare provision in the USA during the 1980s, charting the rise of what was then termed 'the shadow state'. This referred to the variety of civil society groups that stepped in to provide provision, as the state rolled-back and increasingly absolved itself of its social responsibility. This led to a disintegration in the third sector's ability to deliver such services in North American (US) cities as they could not cope with the demand being placed upon them. Partly, this grew from a lack of engagement by the state with civil society and a similar sense of non-engagement, particularly with third sector groups (which will be discussed in more detail shortly) was conveyed currently within GMCR. Hence for many respondents, successful devolution will ultimately rely on the sector being engaged. Whereby they can be enabled to draw upon their connections to communities, especially marginalised groups, to develop their role across GMCR. An important first hurdle for inclusive growth models, therefore, is the requirement for a stronger form of representation within the governance structures of devolution for VCSE groups. This is to not only acknowledge the important role such organisations currently have in $\mathrm{GMCR}^{3}$, but also to think through the ways in which moving forward (and extremely rapid progress is being supported) the sector will be further required to deliver different aspects of devolution to the people of GMCR. This is critical in the context of a significant reduction in central government spending on local economic growth as part of the Government's deficit reduction programme. The National Audit Office reports that over the five-year period $2010 / 11$ to $2014 / 15$ the coalition government will have spent $f 6.2$ billion on local growth programmes, including that spent via RDAs and their legacy, and spend on new funds and structures. By comparison the RDAs spent $f 11.2$ billion over the preceding five-year period 2005/06 to 2009/10 (National Audit Office, 2013). This is also combined with ongoing austerity measures which have and will reportedly cost the GMCR between 2015 to 2020 an estimated f1.4bn from their welfare budgets (see Beatty \& Fothergill, 2016).

Despite the difficult environment surrounding devolution, VCSE groups, although cautious, are also interested to see what it may offer and how they can play an important role within this. Hence, this paper advocates four key reasons that can position the sector as an appropriate interface through which a more inclusive economy might be delivered: one, the need for inclusive governance; two, addressing issues related to operational scales and representation; three, how inequality, in time hinders growth; and fourthly, the need to harness the multifaceted thinking and social innovation of VCSE in order to deliver more inclusive growth.

\footnotetext{
${ }^{3}$ The sector is already deeply significant to the economic status of the city region being worth around £1billion, see Dayson et al. (2013).
} 


\section{Research Context}

This paper and evidence is based on research undertaken by the University of Sheffield and Cardiff University, it is funded by the Economic and Social Research Council (ESRC) ${ }^{4}$. It has been conducted in collaboration with Voluntary Sector North West (VSNW) and the Greater Manchester VCSE (Voluntary, Community and Social Enterprise) Devolution Reference Group. The research has been concerned to address a knowledge gap concerning the role of VCSE groups within City-region Growth strategies and the positioning such groups have within the shaping and roll out of Greater Manchester City-region (GMRC) devolution. The research has involved stakeholder mapping and semi-structured interviews with key VCSE actors operating across the GMCR. The interviews were conducted between August and October 2016. In total, ten interviews were conducted with members from the following VCSE groups:

\begin{tabular}{|l|l|}
\hline Volunteer Action (VA) Oldham & LGBT Foundation \\
\hline Macc & Unlimited Potential \\
\hline Start in Salford & Stroke Association \\
\hline GMCVO & Breakthrough UK \\
\hline $42^{\text {nd }}$ Street & Big Life Group \\
\hline Bolton CVS & Greater Manchester BME Network \\
\hline
\end{tabular}

Table 1 - Participating VCSE Groups

\section{Inclusive Governance for an inclusive City-region}

The parallel contexts of devolution and austerity have created a number of challenges, which in turn raise a series of questions about how governance structures will deal with this and how resources will be effectively deployed to create economic development in Greater Manchester ${ }^{5}$. This raises questions about what economic development in GMCR should look like and who should benefit from future economic growth. To date, within the context of city-region devolution across England and GMCR included, devolution has sought to primarily privilege business interests (Pike et al. 2015). This can be seen in the development of Local Enterprise Partnerships (LEPs) as strategic bodies to shape combined authority economic planning (Pugalis \& Townsend, 2012). In the context of inclusive growth, there is a risk that when such city-region governance arrangements do not involve 'civil society' groups, decision making processes accordingly lack local legitimacy in terms of transparency, scrutiny and accountability. This points towards issues whereby from an instrumental perspective, the processes of devolution are missing out on opportunities to glean local knowledge, engage with communities, support local social innovation and to build suitable partnerships The following section highlights the ways in which the VCSE communities have responded to devolution within the GMCR through organisations such as Greater Manchester Centre for Voluntary Organisations (GMCVO) and the nascent Devolution Reference Group. This material points towards examples of how inclusive

\footnotetext{
${ }^{4}$ ESRC Grant for WISERD Civil Society: Spaces of New Localism (ES/L009099/1).

${ }^{5}$ See Etherington \& Jones (2016) in the context of the Sheffield City Region for similar problems being faced.
} 
governance models can be developed in city-regions, so that devolution can address the stubborn geographies of uneven development and inequality.

In the context of this, the VCSE Devolution Reference Group grew out of a desire for the civil society sector to more actively engage and help shape the City-region in a way that this sector had not seen with previous economic and social development policy initiatives. Devolution represents a different moment in time, where new working relationships are being developed, both reactively and more interestingly, proactively through new geographies of negotiation and engagement. The VCSE Devolution Reference Group, represents a new form of collaborative working, which sits alongside existing institutions in the city-region such as GMCVO. GMCVO has a long history of voluntary (or third) sector representation across the city-region and is also deeply active within the VCSE Devolution Reference Group in continuing to represent the concerns of its members. The scale and pace of devolution and the mechanisms by which GMCA and the UK Government have negotiated such deals has meant that further forms of representation have been sought to find ways to address the new governance structures that are being created within the cityregion. According to one source:

The reference group was set up when we realised that all this was going on around us and nobody was going to come banging down our door...So from that, a coalition of the willing emerged, completely undemocratically but again I think that's part of it. Stop waiting for permission, stop feeling like you have to get every detail right. Because actually things are moving so fast, we have to trust each other to advocate for what our sector wants to achieve collectively (Voluntary Service Leader 1).

The purpose of the VCSE Devolution Reference Group has, therefore, been to find the appropriate ways in which to influence processes of devolution through sectoral collaborations and partnerships. This has been in order to push city-region agendas towards more inclusive approaches that attempt to acknowledge the different ways in which the voluntary sector is positioned throughout Greater Manchester's structures. This is further reflected by another respondent highlighting how by focusing on the restructuring of the public sector alone misses the bigger picture with regards to what could be achieved with a more inclusive governance framework:

The pace of change of devolution has meant a strong inclination towards the public sector thinking about [only] the public sector ... their internal mechanisms and ways of working can override the belief that we're important partners. By having a collective group that is able to rapidly make the case for what we are about and could be about is particularly important at this time (Voluntary Service Leader 2).

The VCSE Devolution Reference Groups, then, represents one model by which within the context of devolution a broad coalition of diverse groups can be brought together alongside pre-existing organisations. The group aims to be representative of (rather than represent), and connect to, the broad spectrum of VCSE activity in GMCR. This takes in how such groups are positioned in different ways with very different approaches. The VSCE Devolution 
Reference group, in its current form is not perfect and the group recognises that it will always need to evolve. Its ability to develop partnerships across a multifaceted range of organisations highlights a model that can be moved forward with devolution to create parallel forms of representation and governance. Such groups involved are at the hard end of delivering and enabling citizens to thrive in the very difficult circumstances of austerity. They have clear social purposes with regards to helping or enabling those in the most difficult circumstances to achieve, in order to 'eradicate' inequality in the GMCR. They also have a strong innovative spirit for delivery in a time of limited resources. This innovation could be harnessed more directly by including such organisations earlier in commissioning processes rather than just as respondents to funding opportunities. In doing this, there could be more attuned responses to inequality whilst giving the processes of commissioning more transparency. In the context of devolution such activities should be folded into the processes of delivering devolution, rather than being a reaction to what is unfolding around VCSE members. This though raises questions of scale and representation and to the wider positioning of civil society as either an 'agent or obstacle' (see Duncan \& Goodwin, 1989) to the development of city-region policy. As 'agent', they risk being complicit in policy which promotes agglomerative economic growth. Whereas an 'obstacle' positioning could see them marginalised further from the representational regime of the city-region which could be precarious for organisations that can often be reliant on various forms of local state funding.

\section{Scale and Representation}

The final point in the last section is also reflected in the following section whereby the creation of the Greater Manchester Combined Authority (GMCA) could paradoxically shift some forms of governance further away from individuals and communities. Although devolution offers potentially more powers at a city-region scale it could also take powers and control away from a local authority scale. Consequently, it can leave many VCSE groups, who often (not always) work within a specific locality, place based community or LA, further away from the processes of decision making and commissioning. This, in turn, potentially reduces their capacity to be an effective advocate for the areas and people they serve and it can also threaten their very existence depending upon the processes of central decision making. According to one commentator:

My concern would be, as a medium sized organisation based and working predominately in Salford, and for other organisations who are smaller than ourselves, what happens if you've got a brilliant, cost effective service and the combined authority wants to commission that service across all of the localities. 'If you are only delivering in Salford and not in the other nine localities, does that mean they are going to commission you on the understanding that you would need to build your organisation's capacity to be able to deliver across the other localities or would they not commission as they would be worried about scaling up and would want to use one of the bigger organisations (Place Based Community Leader 1). 
The description from above, highlights how devolution can potentially be disempowering to actors at the local level. The creation of the city-region, creates a 'jumping of scale' (Cox, 1997; Macleod \& Goodwin, 1999) whereby policy direction and commissioning will reflect combined authority policy decisions. 'Scale Jumping' in this context is the re-defining of territorial relations from the local authority to the city-regional scale in such a way that it circumvents, where possible the 'politics of turf' (Cox, 1989). Scale jumping is therefore a process through which new networks of association can be built to prioritise practices of capital accumulation (Smith, 1984). Against the background of, the city-region devolution, this potentially leaves smaller and more localised providers further away from decisions that may greatly impact upon their organisations future viability. This creates a series of questions for GMCA in terms of how policy can be filtered and interpreted down to the local level. The VCSE sector already has a variety of different organisations working at and delivering across different geographical scales, whether this be at the community, local authority or city-region scales. They have been consistently able to find ways to engage those individuals and groups, which are often hardest to reach or most in need, though this ability is becoming continually strained in the current era of austerity. For a more centralised form of 'local' city-regional governance not to appreciate the local could lead to a number of valuable services, with its nuanced delivery to beneficiaries, being lost in the short term, and possibly longer.

Devolution processes also need to think through ways in which scale also misses by exclusion different formations of community, which are not necessarily place based, such as those concerned with BME, disability, LGBT, homeless and mental health. Such groups exist across the city-region, with specific needs that need to be taken into consideration. Considerable work has gone into the processes of locality planning in GM for health provision but this needs to ensure that this does not miss the needs of different minority groups across the city-region:

My other worry about devolution from an equality perspective is that; in terms of the localism model that everybody is talking about and working on, is that for some people locality isn't their community of identity... That's what many disabled people would say, 'I'm not interested in being disabled, I am a disabled person' and that's it. Now that also might mean that your need or your interface with a service or organisation won't be geographically defined. And also for some people you might actively move away from the geography, in terms of young people who are homeless, young people with mental health problems (Community of Interest Leader 1).

There is, therefore, a need to find ways in which individuals and groups can see appropriate representation within processes of governance. One such approach is to have more involvement of different VCSE groups who form a broad form of representation to different types and forms of communities, who have a history of advocacy within the city-region:

I think it's also about working on different levels. I was very involved in working with colleagues in looking at a voluntary sector response... There is something very 
compelling about not doing this just for ourselves and on our own and actually building a coalition of the willing and recognising that we have much more power doing something together and articulating similar arguments with a range of our colleagues (Community of Interest Leader $\mathbf{2}$ ).

In terms of equality, then, the city-region footprint offers the opportunity for a stronger exploration of how to engage, support and champion communities of identity.

It also allows space to develop a more sophisticated understanding of how scale, engagement, representation and subsidiarity should inter-relate:

The risk is, what's happening is either within GM or moving into GM are big corporate bodies and you could see the in the middle of Manchester, big corporates moving in. Big public sector structures being created and indeed the big charities moving in. The third sector is as guilty of this stuff as anybody else. So we at least need to balance some of that stuff because it's probably going to happen anyway or possibly replace some of that stuff, I think with a much more diverse, smaller medium scale stuff that actually engages the people who need to be engaged (Social Enterprise Leader 1).

This system is not perfect but the scale of operations provided by VCSE groups represents the multifaceted ways in which different organisations work with different communities of geography (city-region through to neighbourhood) and with different communities of identity (Disabled groups, LGBT, BME). Moreover, all this demonstrates the importance of the dynamic between the politics of scale and the ways in which policy and politics is scaled (see Mackinnon piece).

Inequality Hinders Growth

A major observation that we wish to offer through our research is those questions around what sort of growth is being promoted by devolution to GMCR and who benefits from economic agglomeration approaches to creating and growing city-regions? The evidence from our research shows that inequality and social disadvantage actually hinders growth (see for further examples Etherington \& Jones, 2016b; Jonas \& Ward, 2007; Lee, 2016; Lee, Sissons, \& Jones, 2015) or at best, creates the wrong kind of growth due to it not being distributed evenly (see Bowmen et al, 2014). The converse is that those policies, which actively promote labour market inclusion, will contribute to sustainable growth and also assist with maintaining productivity. The current model of growth though restricts access to employment and skills initiatives and hence the city-region will accordingly struggle to meet targets. This is because it does not engage with the existing problems faced by a significant proportion of the population, who are underskilled to access jobs in high growth sectors. This is identified in the below quote as it spatially impacts upon the development of the GMCR:

I think of Greater Manchester as having a ring donut economy, it's a lot like a North American city. So you have thriving city centre, which it didn't have twenty-five years 
ago. The suburbs actually doing ok and then the middle bit. If they do not do something about that, the powers that be will never achieve their economic goals of achieving a fiscal balance for this conurbation (Social Enterprise Leader 1).

The above quite highlights that despite the successes of the GM economy over the last 30 years it has still failed to address core problems as related to uneven development.

Agglomeration focuses growth in specific places, it does not worry about how that growth is then evenly spread, other than for the ideological belief in trickledown economics (Peck, 2012). There is a disconnect at present not just with city-region planning across GM but across the entire process of city-region devolution in the UK. According to one perspective on this:

So one of the challenges we've got at the minute, and that's part of the discussion that has just happened in the meeting today, is this dilemma-or not a dilemma, this disconnect rather, between the VCSE and the work that goes in the whole economy plan around LEPs and everything else that's going on. And there's - social care and the VCS are quite well connected, usually through contract and commissioning but then you've got this whole world around economy, employment and skills that spins close to it but never - rarely collides or isn't connected (Community of Interest Leader 2).

The two previous quotes both highlight a continuing mismatch in the logic of city-region agglomeration, which focuses on GVA uplift, rather than finding ways to provide across the existing populations of $\mathrm{GM}$. The second quote, also highlights an important disconnection in current economic thinking, whereby there needs to be stronger consideration, at a strategic economic level, towards a more holistic approach for employment and skills training. The absence in mainstream discourse about how inequality can be addressed offers an opportunity for voluntary and community sectors to alter the terms of the debate. Members of the VCSE Reference Group can see this and therefore would like to have a stronger voice in order to deliver on a more inclusive growth strategy. This means moving away from an agglomerative growth strategy that does not simply repeat the mistakes of the past. The social innovation already shown by the VCSE sector in delivering on employment and skills training, which attempts to integrate, health and social needs within such training strategies suggests there is wealth of pre-existing knowledge which needs to be accessed by GMCA and LEP. The VCSE sector has a strong record in terms of providing pathways back to work and has been successful in being able to react to changes in economic circumstances. This is again something that economic development agencies like LEPs could better utilise.

Social Innovation, multifaceted thinking and economic growth

VCSE Reference Group members all note how the increased devolution offered to GMCR offers real opportunities to do things differently to the supposed model of growth offered 
by central government, but this opportunity has to be grasped. The devolution of health and social care in GM (unlike in other city-regions) is one such opportunity but this again needs radical rethinking if it is to fulfil its potential. The sector has been one of the most dynamic in terms of thinking through how to deliver services to people and communities that are hardest to reach. The opinion below highlights how the sector is already involved in taking a multifaceted thinking approach:

We need to look at where are the skills and knowledge and solutions to fix any particular problem. Some of it may lie with the people who apparently have the problem, so if you want to solve homelessness, you've got to involve people who have experienced homelessness or who are currently homeless because it would be stupid not to take their...so they would have knowledge that no-one else has. You've got to involve a whole range of other agencies who have touched with that problem in one way or another. And those who have got the overview. Collectively you might then start to come up with an answer to that (Voluntary Services Leader 3).

This desire to socially innovate by connecting up different agents to tackle problems, such as homelessness, exemplifies how new approaches can be found and very much in tune with public sector partner thinking. VCSE groups can play a key strategic role due to their on-theground knowledge and their flexibility in delivering services. Indeed, understanding that the current inequality present in the GMCR is more than just an economic concern and that it is linked to a variety of other multifaceted problems is key to thinking about how groups within VCSE can have a very strong impact in terms of addressing these problems. The VCSE community represents one way in which their complex activity and thinking (from small to large, from person to community and from place to identity) could allow for a stronger response to social inequality and to build a more inclusive economy.

\section{Conclusions}

There is a risk moving forward, that as devolution is delivered across GM and in other cityregions, that not appropriately integrating VCSE groups and arrangements like this into governance structures, will miss an excellent opportunity to redraw the relationships between VCSE, state, business and communities. Combined Authorities and Local Enterprise Partnerships could do worse than listen and then take stock of the knowledge, expertise and innovative ways of working with communities and individuals that the VCSE sector has developed. They also need to think through, if inclusive growth is to be achieved, how can this expertise be better utilised at a strategic level.

We have argued that the VCSE Devolution Reference Group is very much a response to the conditions of devolution in GM but in that response, there is a model alluded to that with further development could address many of the gaps that have developed in the economic led thinking of city-regions. If business interests and state restructuring are left to deliver devolution alone, without more holistically integrating the VCSE community, growth is likely to continue to be exclusive and devolution will not filter down to those places, communities and people who have been left outside economic development. Therefore, in the context of 
inclusive growth, there needs to be stronger acknowledgement of the expertise this sector can bring and they should be given an equal voice alongside business and the public sector in terms of future devolution processes.

As a final caveat to the above and the potential VCSE groups offer devolution and an inclusive economy approach, there is also a need to take a step back and think through, in context of austerity and devolution, some of the pitfalls that could undermine a more inclusive economy. Here, the earlier discussion with regard to Dear \& Wolch (1987) of the neoliberalisation of welfare policy in the USA, is important, the scale of problems that faced 'the shadow state' was well beyond its means to deal with, as such, a whole variety of social problems 'spunout' from this failure to provide a sufficient social welfare safety-net. If this similar turn is taking place in the UK, within the context of city-region devolution and austerity, the UK state at national, combined authority and local state levels alongside business, has to continue to play its part in balancing and supporting the VCSE sector, so that it can have the opportunity to deliver on its aims. 


\section{Bibliography}

Bailey, D., \& Budd, L. 2016. Devolution and the UK Economy. London: Rowman \& Littlefield International.

Beatty, C., \& Fothergill, S. 2016. The Uneven Impact of Welfare Reform. Sheffield: Sheffield Hallam University.

Beel, D., Jones, M., \& Jones, I. R. 2016. Regulation, governance and agglomeration : making links in city-region research. Regional Studies, Regional Science, 3 (1), 509-530.

Bowman, D., Froud, J., Joha, S., Law, J., Leaver, A., Moran, M., \& Williams, K. 2014. The end of the experiment? (Manchester Capitalism). Manchester: Manchester University Press.

Cox, K. . 1997. Spaces of dependence, spaces of engagement and the politics of scale, ore looking for local politics. Policitcal Geography, 17(I), 1-22.

Dayson, C., Eadson, W., Sanderson, E., \& Wilson, I. 2013. Greater Manchester State of the Voluntary Sector 2013. Sheffield: Sheffield Hallam University.

Dear, M. J., \& Wolch, J. R. 1987. Landscapes of despair : from deinstitutionalization to homelessness. Cambridge: Polity Press.

DeVerteuil, G. 2016. Resilience in the post-welfare inner city : voluntary sector geographies in London, Los Angeles and Sydney. Bristol: Polity Press.

Duncan, S., \& Goodwin, M. 1989. The Local State and Uneven Development. London: Polity Press.

DWP. 2016. Improving Lives The Work, Health and Disability Green Paper. London: HM Government.

Etherington, D., \& Jones, M. 2016a. Devolution and Disadvantage in the Sheffield City Region: An assessment of employment, skills, and welfare policies. Sheffield: Univeristy of Sheffield.

Etherington, D., \& Jones, M. 2016b. The city-region chimera: the political economy of metagovernance failure in Britain. Cambridge Journal of Regions, Economy and Society, 9(2), 371-389.

Haughton, G., Deas, I., Hincks, S., \& Ward, K. 2016. Mythic Manchester: Devo Manc, the Northern Powerhouse and rebalancing the English economy. Cambridge Journal of Regions, Economy and Society, 9(2), 355-370.

Heinrich, V. F. 2005. Studying civil society across the world: Exploring the Thorny issues of conceptualization and measurement. Journal of Civil Society, 1(3), 211-228.

Jonas, A. E. G., \& Ward, K. 2007. Introduction to a Debate on City-Regions: New Geographies of Governance, Democracy and Social Reproduction. International Journal of Urban and Regional Research, 31(1), 169-178.

Jonas, a. E. G. 2012. City-regionalism: Questions of distribution and politics. Progress in Human Geography, 36(6), 822-829.

Jones, R. 2012. State encounters. Environment and Planning D: Society and Space, 30(5), 805-821.

Lee, N. 2016. Powerhouse of Cards? Understanding the "Northern Powerhouse." Regional Studies, 51(3), 478-489.

Lee, N., Sissons, P., \& Jones, K. 2015. The Geography of Wage Inequality in British Cities. Regional Studies, 3404(September), 1-14. 
Macleod, G., \& Goodwin, M. 1999. Reconstructing an urban and regional political economy : on the state, politics, scale, and explanation. Policitcal Geography, 18, 697-730.

National Audit Office. 2013. Funding and Structures for Local Economic Growth. London: HM Government.

O'Brien, P., \& Pike, A. 2015. City Deals, Decentralisation and the Governance of Local Infrastructure Funding and Financing in the UK. National Institute Economic Review, (233), 14-26.

Peck, J. 2012. Austerity urbanism. City, 16(6), 626-655.

Pike, A., Marlow, D., McCarthy, A., O’Brien, P., \& Tomaney, J. 2015. Local institutions and local economic development: the Local Enterprise Partnerships in England, 2010-. Cambridge Journal of Regions, Economy and Society, 8, 185-204.

Pugalis, L. \& Townsend, A. R. 2012. Rebalancing England: sub-national development (once again) at the crossroads. Urban Research \& Practice, 5(1), 157-174.

RSA. 2016a. Inclusive Growth Commission Emerging Findings Foreword. London: RSA.

RSA. 2016b. Inclusive Growth Commission Prospectus of Inquiry. London: RSA.

RSA. 2016c. Inclusive growth for people and places. London: RSA.

Sheffield.ac.uk. 2016. Academic leading trial to support residents with long-term health conditions or disabilities. Available at https://www.sheffield.ac.uk/faculty/social-sciences/news/adamwhitworth-leading-sheffield-trial-1.658976. Accessed 23/2/2017.

Smith, N., 1984. Uneven Development: Nature, Capital and the Production of Space. Blackwell, Oxford.

Waite, D., Maclennan, D., \& O'Sullivan, T. 2013. Emerging city policies: Devolution, deals and disorder. Local Economy, 28(7-8), 770-785. 